\title{
Adherence to treatment in inflammatory bowel disease
}

\author{
A. López San Román, F. Bermejo ${ }^{1}$, E. Carrera, M. Pérez-Abad ${ }^{2}$ and D. Boixeda \\ Service of Gastroenterology. Hospital Ramón y Cajal. Madrid. 'Service of Digestive Diseases. Hospital de Fuenlabrada, \\ Fuenlabrada, Madrid. ${ }^{2}$ Service of Biochemistry. Hospital Ramón y Cajal. Madrid, Spain
}

\begin{abstract}
Aim: adherence to therapy is important to ensure success. We wanted to explore this feature in patients with inflammatory bowel disease.

Patients and methods: we explored adherence to treatment and its modifiers in 40 patients with inflammatory bowel disease using a battery of tests.

Results: a $67 \%$ of patients (95\% CI: $51-81 \%$ ) acknowledged a certain degree of involuntary nonadherence, and 35\% (95\% CI: 20$51 \%$ ) of voluntary nonadherence. Overall, $72 \%$ (95\% CI: 56-85\%) of patients had some form of nonadherence. An objective correlation of these self-reported data was assessed by the determination of urine salicylate levels in the subset of patients treated with mesalazine or its derivatives (15 cases). Two of them (13\%) had no detectable urinary drug levels, indicating complete nonadherence.

Voluntary nonadherence was higher in patients with lower scores in the intestinal $(p=0.02)$ and social areas $(p=0.015)$ of IBDQ-32, as well as in those with less active Crohn's disease ( $p<$ 0.005), patients with high depression scores and high patientphysician discordance $(p=0.01)$, patients with long-standing disease $(p=0.057)$, patients who considered themselves not to be well informed about the treatment they were getting $(p=0.04)$ or who trusted their attending physicians less $(p=0.03)$.

Conclusions: intentional nonadherence to therapy is prevalent among patients with inflammatory bowel disease. A correction of factors associated to poor adherence could lead to higher therapeutic success.
\end{abstract}

Key words: Inflammatory bowel disease. Treatment. Adherence to treatment.

López San Román A, Bermejo F, Carrera E, Pérez-Abad M, Boixeda D. Adherence to treatment in inflammatory bowel disease. Rev Esp Enferm Dig 2005; 97: 249-257.

Recibido: 20-05-04.

Aceptado: 23-11-04.

Correspondencia: Antonio López San Román. Servicio de Gastroenterología. Hospital Ramón y Cajal. Ctra. de Colmenar Viejo, km. 9,100. 28034 Madrid.

\section{INTRODUCTION}

The treatment of any disease or condition has to pursuit a double aim, which probably stands clear for everybody: to achieve a benefit for the patient without causing significant adverse events. Different steps are taken to ensure this. Drugs are born in the aseptic world of laboratories and experimental sciences, pass through preclinical and clinical studies, are analyzed in depth by marketing experts of manufacturing companies, and finally reach the prescribing physician, to whom they are frequently described as a significant contribution to the therapy of a given condition. Only rarely is the patient's opinion taken into account through this process: the rationale behind this may be that nobody doubts that patients only want to get better and are thus going to take the prescribed treatment without further discussion... or do they?

Maybe we do not understand patient needs, maybe our concept and their concept of "response" are not the same; the truth is that the practical application of any type of drug has to take into account a fundamental element. Otherwise, failure or, at least, significantly worse-thanexpected results can ensue. This key element is adherence $(1,2)$. Adherence can be defined as the active and informed participation of patients in treatment decisions $(1,3)$; this has an immediate effect: compliance with proposed medical measures will be optimal, or at least will reach a minimum standard. This concept, adherence, is thus wider than compliance and should be preferred. When talking about compliance, the patient is left as a mere follower of his or her physician's indications with no active role. Care must be exerted in the adaptation of this term to the various languages: an example is Spanish, where adhesion should be used instead of adherence (4). Nevertheless, we think that compliance can still be used (knowing the limitations of the term) when designing the degree to which a given patient does or does not follow a suggested treatment. 
Inflammatory bowel disease (IBD) represents a highrisk situation for nonadherence: a chronic illness, affecting young patients, with an unpredictable course, with naturally-occurring long inactive periods, and sometimes managed by non-convenient or difficult-to-follow therapies, like enemas $(1,2,5)$. Patients must have a profound conviction that the proposed therapy is both necessary and convenient to solve or palliate their problem. More so in prophylactic therapy, a situation in which we demand from the patient a deep faith in our recommendations.

Our aim has been to study in a monographic IBD clinic the degree of adherence to therapy of those patients, as well as to detect the types of factors influencing this feature.

\section{MATERIAL AND METHODS}

Within an IBD outpatient clinic at a University Hospital within the Spanish National Health System, we studied a consecutive series of 40 patients during December 2003 and January 2004. We excluded new patients, urgent consultations, persons with comorbid conditions that could act as confounders in data gathering and interpretation, and persons unable to fill up tests and questionnaires.

With a previous informed consent, we applied the following tests and items:

- Recollection of demographic data: age, sex, income level, educational level.

-Data about the patient's disease: time of diagnosis, years with symptoms, current activity indices (HarveyBradshaw in Crohn's disease and Lichtiger's clinical index in ulcerative colitis) $(6,7)$.

-Current treatment: drugs, doses, schedules (these data were contrasted with clinical records).

- Hospital anxiety \& depression score (8).

-Quality-of-life measurement tool for patients with IBD (IBDQ-32) (9), not specifically validated in our country.

- Self-report of adherence to treatment (1) (Fig. 1).

-Patient-physician agreement scale (PPAS), a specif-

\begin{tabular}{|clll|}
\hline 1 Did you sometimes forget to take your & & \\
medication? & $\begin{array}{l}\text { Were you careless at times about taking your } \\
\text { medication? }\end{array}$ & True & False \\
3 & $\begin{array}{c}\text { When you felt better, did you sometimes stop } \\
\text { taking your medication? }\end{array}$ & True & False \\
$4 \quad \begin{array}{l}\text { If you felt worse when you took your medication, } \\
\text { did you sometimes stop taking your medication? }\end{array}$ & True & False \\
\hline
\end{tabular}

Fig. 1.- True/False questions used to explore adherence to treatment. ically designed measure instrument of this parameter, comprising a series of questions answered by a visual analogic scale, and exploring specific aspects of health perception and the impression about the current visit (1); this instrument has not been specifically validated in Spain, and was provided by its designer; interested investigators may apply following the instructions expressed in her publication

- Simple questions aiming to explore several factors that might be modifying adherence (Table I), answered by a visual analogic scale ranging from 0 to 10 ; results are translated numerically.

Table I. Simple questions used to explore possible modifiers of adherence to treatment

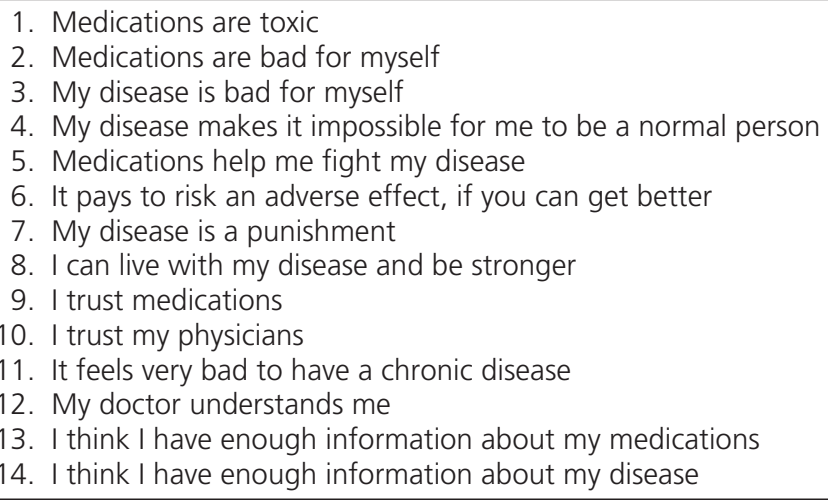

After the consultation, the attending physician (ALS) calculated activity indexes and filled in the corresponding section of PPAS (1).

In patients taking mesalazine or derivatives a urine sample was taken immediately after the consultation. These samples were analyzed for salicylates by fluorescence polarity immunoassay (FPIA); this technique has been shown to be adequate to evaluate the presence of 5aminosalicylic acid and its metabolites (10).

Results were analyzed using the SPSS software (v 10.0). Confidence intervals were calculated at 95\%. A "p" value below 0.05 was considered statistically significant. For quantitative variables, the arithmetic mean and standard deviation were calculated. For continuous variables, a t test was used for mean comparison. Categoric variables were compared using the Chi square test $\left(\chi^{2}\right)$, except when less than 5 registers were expected, in which case we used Fisher's test.

\section{RESULTS}

We included 40 patients, 20 males and 20 females. Mean age was $39.4 \pm 10.5$ years. Diagnosis was Crohn's disease (CD) in 28 cases $(70 \%)$, and ulcerative colitis (UC) in $12(30 \%)$. 
In patients with $\mathrm{CD}$, the mean Harvey-Bradshaw index reached $2.6 \pm 2.9$ points. In UC patients, mean Lichtiger's index was $4.1 \pm 2.5$ points.

All questions were answered by $100 \%$ of patients.

Self-reported adherence separately explored nonintentional and intentional nonadherence. Some degree of nonintentional adherence was present in 67\% (95\% CI: $51-81 \%$ ) of cases. More precisely, $60 \%$ (95\% CI: $43-$ $75 \%$ ) of patients answered positively the question "Did you forget to take your medication?", whilst 38\% (95\% CI: $22-54 \%$ ) did so for "were you careless at times about taking your medication?"

In turn, $35 \%$ (95\% CI: $20-51 \%)$ of patients reported some degree of voluntary nonadherence. Fifteen percent (95\% CI: 5-29\%) answered affirmatively the question "when you felt better, did you sometimes stop taking your medication?", and a further 25\% (95\% CI: $12-41 \%)$ the question "if you felt worse when you took your medication, did you sometimes stop taking your medication?".

Overall, $72 \%$ (95\% CI: $56-85 \%$ ) of patients acknowledged either type of nonadherence (voluntary or involuntary).

An objective correlation of adherence to treatment was obtained by the determination of urinary levels of salicylates in the subgroup of patients treated with mesalazine or its derivatives (15 cases). Two of them (13\%) had no detectable levels, indicating complete nonadherence.

We studied any possible associations between intentional nonadherence and the results obtained by patients in the various tests and scales applied. A higher degree of intentional nonadherence was associated with:

- Low scores in the intestinal $(\mathrm{p}=0.02)$ and social $(\mathrm{p}$ $=0.015)$ areas of IBDQ-32.

- Patients with Crohn's disease and low Harvey-Bradshaw scores (patients with less active disease) $(\mathrm{p}<$ 0.005).

- Patients with high depression scores and high patient-physician discordance $(\mathrm{p}=0.01)$.

-Patients with longer-standing IBD $(p=0.057)$.

- Patients who did not consider themselves to be adequately informed about their treatment $(p=0.04)$.

- Patients who trusted their treating physicians less ( $\mathrm{p}$ $=0.03$ ).

\section{DISCUSSION}

A medical act is not only defined by the interaction between patient and physician, but also by its result. We should try to go further than merely establishing a correct diagnosis and prognosis, and indicating an adequate therapy. How our indications are followed is a key to the evaluation of treatment efficacy and safety, thus closing the cycle of medical assistance.

To this traditional standpoint we should add the disquieting but interesting conviction that patients have a lot to say in all this process. Let us consider briefly how our therapeutical indications influence and interfere with a person's lifestyle: new timetables have to be designed, daily activities have to be interrupted, time and duration of meals and maybe other activities, like sleep, have to be revised. Additionally, drugs are notorious by their adverse effects, as we know, and these can make therapy an enduring trial. Therapy is frequently difficult to follow because a drug is unpalatable, or because of the inconvenience of that drug administration (let us recall here the inconvenience of enemas).

In summary, it is useful to stop and think that, when we suggest the therapy a patient needs to get over her or his illness, we are demanding an effort and a collaboration to achieve a happy ending. If the patient just follows our indications, we can explore compliance. Some think that this concept has been surpassed (1-3). If a patient understands, suggests, and participates in therapeutic decisions, then we are promoting her or his adherence to therapy.

Adherence to therapy determines the degree of therapeutic compliance, and this obviously modifies the body's exposure to a given drug. This, in turn, determines a reduction of the expected and adverse effects. When we prescribe a therapy, we take it for granted that the dosage and duration that we indicate will be the real ones. However, this is not always true. Beside the normal degree of inadvertent nonadherence, it has been known for long that, under some circumstances, adherence will be diminished furtherly. In Internal Medicine, therapies for diabetes, arterial hypertension or dyslipidemia are hampered by a high degree of nonadherence (11-13). The same observation, maybe for different reasons, can be made for patients with HIV infection (13) or tuberculosis $(14,15)$.

In the field of Gastroenterology, some therapies carry a high nonadherence risk, like those of gluten-sensitive enteropathy, Helicobacter pylori infection or chronic hepatitis C (16). Digestive diseases are, in fact, a high-risk group for nonadherence $(13,16)$.

Finally, in IBD patient nonadherence should be feared and even expected (1). This has been stated by different authors.

In a study exploring the compared efficacy of mesalazine suppositories and hydrocortisone enemas in patients with distal ulcerative colitis (5), it was suggested that the better results observed in the mesalazine group could be partly explained by the easier application of suppositories and a higher compliance.

Adherence was specifically assessed in another study (17), which detected the presence of sulphapyridine in the serum of patients with ulcerative colitis under maintenance therapy with suphasalazine. In $21(12 \%)$ of 175 outpatients, sulphapyridine could not be detected, reflecting complete nonadherence. Those results are practically identical to ours (13\% of complete nonadherence).

Another study (18) detected $43 \%$ of nonadherent patients. Dosage divided in three daily doses was an inde- 
pendent predictor of nonadherence (OR: 3.1), as was full time employment. In 12 cases $(12 \%)$ the drug or its metabolites could not be detected in the urine, thus revealing absolute noncompliance, and this was associated with the presence of depression (OR: 10.5) and threetimes-daily dosing (OR: 3.7)

A very interesting contribution has recently explored the influence on adherence of the interaction between patient and physician (1). Forty-one percent of the interviewed IBD patients acknowledged some degree of nonadherence - in two thirds of them this nonadherence was involuntary. Among other factors, the following were predictors of nonadherence: low disease activity, the fact of being a new patient, long-standing disease and the presence of disagreement in the patient's and physician's perception of the extent to which the consultation had fulfilled the patient's expectations, although this effect was only detectable in stress-free patients.

And what happens if adherence is not complete? Does this change treatment outcomes? In a very interesting investigation (2), 99 patients with quiescent ulcerative colitis were prospectively followed. All were getting prophylactic therapy with mesalazine, and it was possible to find out (through drug dispensation control) what percentage of the prescribed drug was being actually purchased by patients. Adherence was considered satisfactory if more than $80 \%$ of prescriptions were filled. It was found that, whilst adherent patients virtually remained clinically inactive, the risk of relapse increased fivefold in nonadherent patients. Nearly $70 \%$ of patients with disease reactivation did not have an adequate degree of adherence. The same group described some years ago (19) that nonadherence was higher in males, persons without a stable affective relationship, or those receiving more than 4 drugs.

In summary, it seems that adherence is important but not always optimal. Predictors of low adherence include long-standing disease, inactive disease, male gender, lack of a stable affective relationship, deteriorated patientphysician relationship (more specifically, low concordance between both), and depression.

Our results are partly in accordance with that experience. The incomplete adherence rate is in the same range as described by other authors, and nonintentional adherence is always higher. But in fact, intentional nonadherence is more significant, and probably the most important target to correct. In our experience, complete nonadhesion $(13 \%)$ is in accordance with previous data. For Crohn's disease, low activity was associated with low adherence; maybe the small number of ulcerative colitis patients precluded a similar result. High depression scores (in cases of insufficient patient-physician concordance) altered quality of life in the intestinal and social domains (according to IBDQ), and long-standing disease also predicted low adherence. The use of open questions showed that nonadherence increased in patients who considered themselves not to be adequately informed about the drugs they were taking, and in patients who trusted their physi- cians less. This opens two very important ways to improve adherence: better patient information and a better patient-physician relationship. This is in agreement with patient opinions (20). Achieving these goals in a busy practice is somehow utopical. Maybe a collaboration with nurses, patient associations, and pharmacy clerks could be a key to success. The identification and treatment of depressive patients is another priority.

In summary, we may consider that adherence to therapy in IBD patients is insufficient, and parallels what has been described in other countries. Several factors are associated with nonadherence, some of which stand out as more amenable to correction: the keys include the avoidance of three-times-daily dosages, treatment of depression, better information about prescribed drugs, and improved patient-physician relationship.

\section{ACKNOWLEDGMENTS}

To Miquel A. Gassull, for he inspired our interest in that curious and important feature of Gastroenterology and, more so, of inflammatory bowel disease.

To Maida Sewitch, for her comments, her contribution and her patient explanations about the use of the patientphysician agreement scale.

To José Antonio Ibáñez, for his help with the use of instruments used in the measurement of quality of life, anxiety, and depression. To the Drug Monitoring Lab and Statistics Unit at Hospital "Ramón y Cajal".

\section{CONFLICT OF INTERESTS}

Dr. López San Román has lectured or acted as an expert at the requirement of the three manufacturers of mesalazine in Spain (FAES, Ferring, Schering-Plough).

Dr. Bermejo was accorded a grant by Schering-Plough Spain, during the data gathering phase of the present study.

\section{REFERENCES}

1. Sewitch MJ, Abrahamowicz M, Barkun A, Bitton A, Wild GE, Cohen $\mathrm{A}$, et al. Patient nonadherence to medication in inflammatory bowel disease. Am J Gastroenterol 2003; 98: 1535-44.

2. Kane S, Huo D, Aikens J, Hanauer S. Medication nonadherence and the outcomes of patients with quiescent ulcerative colitis. Am J Medicine 2003; 114: 39-43

3. Dracup K, Baker DW, Dunbar SB, Dacey RA, Brooks NH, Johnson JC, et al. Management of heart failure. II. Counseling, education, and lifestyle modifications. JAMA 1994; 272: 1442-6.

4. Diccionario de la lengua española. 22a edición. Madrid: Espasa Calpe, 2001.

5. Farup PG, Hovde O, Halvorsen FA, Raknerud N, Brodin U. Mesalazine suppositories versus hydrocortisone foam in patients with distal ulcerative colitis. A comparison of the efficacy and practicality of two topical treatment regimens. Scand J Gastroenterol 1995; 30: 164-70. 
6. Harvey RF, Bradshaw JM. A simple index of Crohn's-disease activity. Lancet 1980; 1: 514.

7. Lichtiger SC, Present DH, Kornbluth A, Gelernt I, Bauer J, Galler G. Cyclosporin in severe ulcerative colitis refractory to steroid therapy. N Engl J Med 1994; 330: 1841-5.

8. Tejero A, Guimerá EM, Farré JM, Peri JM. Uso clínico del HAD (Hospital Anxiety and Depression Scale) en población psiquiátrica. Un estudio de su sensibilidad, fiabilidad y validez. Rev Depto Psiquiatría Facultad Med Barna 1986; 13: 233-8.

9. Lopez-Vivancos J, Casellas F, Badia X, Vilaseca J, Malagelada JR. Validation of the Spanish version of the inflammatory bowel disease questionnaire on ulcerative colitis and Crohn's disease. Digestion 1999; 60 (3): 274-80.

10. Shaw IS, Jobson BA, Silverman D, Ford J, Hearing $\mathrm{SD}$, Ball $\mathrm{D}$, et al. Is your patient taking the medicine? A simple assay to measure compliance with 5aminosalicylic acid-containing compounds. Aliment Pharmacol Ther 2002; 16: 2053-9.

11. Schroeder K, Fahey T, Ebrahim S. How can we improve adherence to blood pressure-lowering medication in ambulatory care? Systematic review of randomized controlled trials. Arch Intern Med 2004; 164: 722-32.

12. Pasternak RC. Report of the Adult Treatment Panel III: the 2001 National Cholesterol Education Program guidelines on the detection, evaluation and treatment of elevated cholesterol in adults. Cardiol Clin 2003; 21: 393-8.
13. DiMatteo MR. Variations in patients' adherence to medical recommendations: a quantitative review of 50 years of research. Med Care 2004; 42: 200-9.

14. Sánchez-Arcilla I, Vílchez JM, García de la Torre M, Fernández X, Noguerado A Infección tuberculosa latente en población indigente. Comparación de dos pautas terapéuticas. Med Clin (Barc) 2004; 122: 57-9.

15. Jasmer RM, Nahid P, Hopewell PC. Latent tuberculosis infection. New England J Med 2002; 347: 1860-6.

16. Levy RL, Feld AD. Increasing patient adherence to gastroenterology treatment and prevention regimens. Am J Gastroenterol 1999; 94: 1733-42.

17. Van Hees PA, van Tongeren JH. Compliance to therapy in patients on a maintenance dose of sulfasalazine. J Clin Gastroenterol 1982; 4: 333-6.

18. Shale MJ, Riley SA. Studies of compliance with delayed-release mesalazine therapy in patients with inflammatory bowel disease. Aliment Pharmacol Ther 2003; 18: 191-8.

19. Kane SV, Cohen RD, Aikens JE, Hanauer SB. Prevalence of nonadherence with maintenance mesalamine in quiescent ulcerative colitis. Am J Gastroenterol 2001; 96: 2929-33.

20. Casellas F, Fontanet G, Borruel N, Malgelada JR. Opinión de los pacientes con enfermedad inflamatoria intestinal sobre la atención sanitaria recibida. Rev Esp Enferm Dig 2004; 96: 174-84. 